\title{
Strain Ultrasound Elastography in the Achilles Tendon of Ankylosing Spondylitis Patients Treated With Anti-TNF- $\alpha$ : A Preliminary Study
}

\author{
ENRICO M. ZARDI ${ }^{1}$, MARIA ELENA PIPITA ${ }^{1}$, CHIARA GIORGI ${ }^{2}$, \\ ANTONELLA AFELTRA ${ }^{3}$, NICOLA MAFFULLI ${ }^{4,5,6}$ and FRANCESCO FRANCESCHI ${ }^{7}$ \\ ${ }^{1}$ Internistic Ultrasound Service "Campus Bio-Medico" University, Rome, Italy; \\ ${ }^{2}$ Radiology Department, S. Maria della Misericordia Hospital, Urbino, Italy; \\ ${ }^{3}$ Immunorheumatology "Campus Bio-Medico" University, Rome, Italy; \\ ${ }^{4}$ Department of Musculoskeletal Disorders, School of Medicine and Surgery, University of Salerno, Salerno, Italy; \\ ${ }^{5}$ Centre for Sports and Exercise Medicine, Mile End Hospital, \\ Queen Mary University of London, Barts and the London School of Medicine and Dentistry, London, U.K.; \\ ${ }^{6}$ School of Medicine, Institute of Science and Technology in Medicine, Guy Hilton, Keele University, Newcastle, U.K.; \\ ${ }^{7}$ Department of Orthopaedic and Trauma Surgery, Campus Biomedico University, Rome, Italy
}

\begin{abstract}
Background/Aim: To compare patients affected by ankylosing spondylitis (AS) treated with anti-TNF- $\alpha$ for two years with controls in terms of Achilles tendon stiffness, ultrasound structure and thickness. Patients and Methods: Bmode ultrasound evaluation and strain ultrasound elastography were performed in longitudinal and transverse planes on 22 Achilles tendons of 11 AS patients and 26 of 13 controls. Results: There were no significant differences in thickness and stiffness of the Achilles tendon between AS patients and controls, except for an increased thickness in the middle third of the tendon in the AS patients ( $p=0.04)$. The Achilles tendon stiffness ratio of AS patients was $1.02 \pm 0.36 \mathrm{vs} .1 .14 \pm 0.38$ in the controls ( $p=0.2)$. Conclusion: AS patients had an Achilles tendon thickness greater than controls at the middle third, but no difference in the stiffness was found among them. Strain ultrasound elastography may be useful to exclude early changes in mechanical properties of tendons.
\end{abstract}

Ankylosing spondylitis (AS) is a chronic inflammatory spondyloarthritis, the diagnosis of which is based upon

This article is freely accessible online.

Correspondence to: Dott. E. M. Zardi, Head of Internistic Ultrasond Service, Campus Bio-Medico University of Rome, Via Àlvaro del Portillo, 200, 00128 Rome, Italy. Tel: +39 06225411432, e-mail: e.zardi@unicampus.it

Key Words: Achilles tendon, ankylosing spondylitis, anti-TNF- $\alpha$ therapy, elastography, ultrasound. clinical, laboratory, and imaging assessment (1). In AS, inflammation affects the axial skeleton, from cervical tract to sacro-iliac joints, and, not infrequently, the ankles. The Achilles tendon is often involved in patients who develop tendinitis and enthesitis, causing pain and stiffness at the posterior aspect of the heel.

Ultrasound is an effective tool in the evaluation of the Achilles tendon in patients with AS (2) given the standardization of the definition and of the detection of spondyloarthritis-related enthesitis (3) and the accuracy in detecting peripheral joint features $(4,5)$; the implementation of power Doppler increased its diagnostic performance (6, 7). Ultrasound can also be used to evaluate in a longitudinal fashion the degree of enthesitis and thus to monitor the clinical course of spondyloarthritis (8).

Ultrasound may also be employed in monitoring the therapeutic response to TNF- $\alpha$ antagonists in patients with Achilles enthesitis $(9,10)$. Furthermore, the continued development of imaging techniques has allowed the introduction of elastography in many commercial ultrasound devices (11-13).

Recently, ultrasound elastography has been used in several cases to identify changes in stiffness of muscles and tendons (14-16). Moreover, ultrasound elastography is more sensitive than B-mode ultrasound in identifying changes in mechanical properties of tendons (14) as confirmed by histological diagnosis (17).

Since little information is available on the effect of antiTNF- $\alpha$ therapy on Achilles tendon of AS patients (18), ultrasound evaluation of this tendon was performed to evaluate the enthesis and the diameter of Achilles tendon in 
patients with AS and in controls through the use of grey scale and power Doppler ultrasound. Moreover, using strain ultrasound elastography, the stiffness of the Achilles tendon was evaluated in both groups.

\section{Patients and Methods}

Eleven AS patients ( 7 males, 4 females; median age $59 \pm 9$ years) diagnosed according to the classification criteria of the Assessment of Spondylo Arthritis Society (ASAS) (19), were enrolled in this descriptive report. They were treated for 2 years with TNF antagonists in accordance with the ASAS guidelines (20).

Disease activity and function of ankylosing spondylitis were determined by calculating Bath Ankylosing Spondylitis Disease Activity Index (BASDAI), Bath Ankylosing Spondylitis Functional Index (BASFI), and Bath Ankylosing Spondylitis Metrology Index (BASMI) scores.

Clinical data and activity indexes of these patients are shown in Table I.

The control group was composed of 13 individuals without any rheumatic diseases and osteoarthritis ( 4 males, 9 females; median age $62 \pm 7$ years). Patients and controls under 18 years and those with a known history of diabetes, inflammatory bowel diseases, sportsrelated or traumatic injuries, surgery or congenital ankle malformations were excluded from the study. Patients and controls had overlapping clinical features.

This study was approved by the institutional ethics committee [(ComEt CBM) (protocol number: 23/15 OSS, 21 July 2015)], and all subjects gave their written informed consent to participate in the study.

Ultrasound. Ultrasound evaluation included B-mode and strain ultrasound elastography, and was performed in the longitudinal and transverse planes by an expert investigator with more than ten years of experience in musculoskeletal ultrasound. In AS patients the ultrasound was performed two years after the start of treatment. A total of 48 tendons were examined: 22 tendons of AS patients, and 26 tendons of controls. The ultrasound assessment was made according to the Outcome Measures in Rheumatology Clinical Trials (OMERACT) definitions (21).

With the patient prone and the gastrocnemius soleus muscle complex relaxed, a standard ultrasound scan was taken of the Achilles tendon of both legs, including the muscle and the insertion of the calcaneus (22). A Toshiba Aplio 500 platinum ultrasound machine (Toshiba Medical Systems Corporation, Otawara, Tochigiken, Japan), equipped with an elastography-compatible high definition linear multifrequency probe (7-15 MHz) was used. The examiner was blinded to the clinical condition of the subject.

Grey scale imaging was used to measure the proximal, middle and distal diameter of the tendon, evaluate tendon echostructure, and scan the entheseal area to ascertain the presence or absence of retrocalcaneal bursitis, enthesophytes and calcaneal erosions. Power Doppler and SMI (Superb Micro-Vascular Imaging, a system able to expand the range of visible blood flow and provide visualization of low velocity microvascular flow) were used to evaluate the presence of neovascularization.

Toshiba's strain ultrasound elastography, which provides a realtime semi-quantitative means of measurement and a dynamic visual display of tissue stiffness in a user-defined region of interest, was used to quantify stiffness.
Table I. Main clinical and demographic features of 11 patients with ankylosing spondylitis.

\begin{tabular}{lc}
\hline Male/Female & $7 / 4$ \\
Age & $59 \pm 9$ \\
Disease duration & $7.15 \pm 4.03$ \\
BASDAI & $2.66 \pm 2.49$ \\
BASMI & $4.32 \pm 2.1$ \\
BASFI & $30 \pm 7.4$ \\
ESR, $\mathrm{mm} / \mathrm{h}$ & $10 \pm 4$ \\
$\mathrm{CRP}, \mathrm{mg} / \mathrm{l}$ & $0.4 \pm 0.3$ \\
& \\
Treatment & \\
CSs & $3 / 11$ \\
NSAIDs & $6 / 11$ \\
DMARDs & $4 / 11$ \\
TNF antagonist (continued for 2 years) & $11 / 11$ \\
\hline
\end{tabular}

Table II. Proximal, medial and distal segment of Achilles tendon diameter (in $\mathrm{mm}$ ) and ultrasound elastography.

\begin{tabular}{lccc}
\hline Tendon Diameter & Patients & Healthy controls & $p$-Value \\
\hline Proximal third & $1.72 \pm 0.26$ & $1.62 \pm 0.30$ & 0.58 \\
Middle third & $4.74 \pm 0.81$ & $4.44 \pm 0.58$ & 0.04 \\
Distal third & $4.59 \pm 0.66$ & $4.24 \pm 0.84$ & 0.18 \\
& & $1.14 \pm 0.38$ & 0.2 \\
Tendon's ultrasound & $1.02 \pm 0.36$ & & \\
\hline
\end{tabular}

Stiffness measurements were assessed by the same sonographer taking a longitudinal scan with the probe perpendicular to the skin, applying repetitive, mild, uniform pressure and avoiding lateral movements to the middle area of the Achilles tendon. The amount and uniformity of the compression were standardized via observation of an onscreen pressure graph.

The strain ultrasound elastographic image, obtained in a longitudinal view, appeared as a color translucent map superimposed on the grey scale B-mode images; a specific stiffness of the tendon corresponded to a given color. The stiffness value was obtained using a Q-Box set at a standard sized of 3.0 $\mathrm{mm}$, taking care that three Q-Box were placed at three different points at the same depth level on the middle third of Achilles tendon, while a fourth Q-Box at a separate depth for the muscle tissues surrounding the tendon (Figures 1 and 2). The mean stiffness ratio of the Achilles tendon was automatically calculated by the machine.

The numerical result of the stiffness ratio (relative hardness of the tissue in the Q-Box compared to the adjacent tissue) was printed and the data entered in an Excel Database; the mean value of the three measurements of the right and left Achilles tendon, in both the AS patients and the controls, was used for statistical analysis.

Ethical approval. All procedures performed in studies involving human participants were in accordance with the ethical standards of the institutional and/or national research committee and with the 


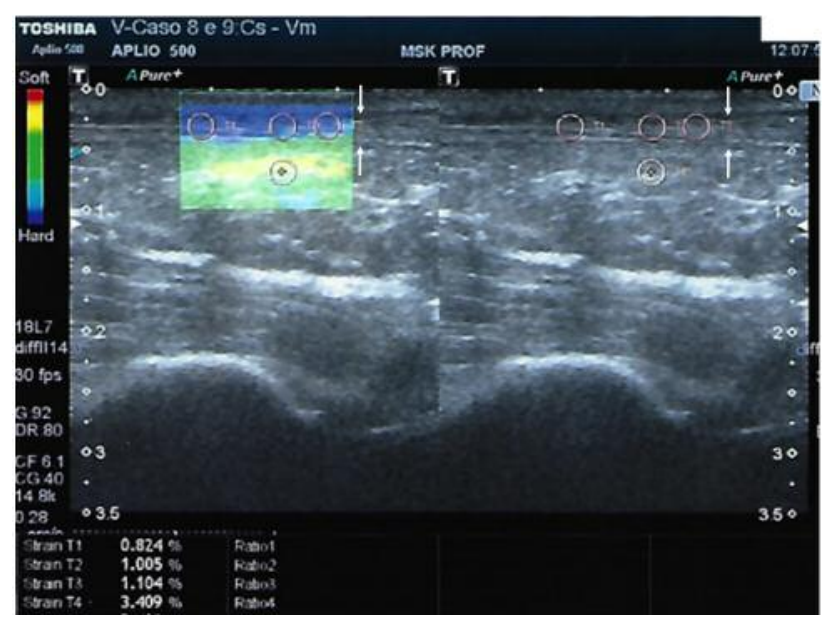

Figure 1. Longitudinal strain ultrasound elastography image of the Achilles tendon of an AS patient. The superficial and deep surfaces of the Achilles tendon are identified with white arrows. The stiffness of Achilles tendon is measured in three points (Q-Boxes), and compared with another point $(Q-B o x)$ in the deep tissue. The boxes are the regions of interest for the quantitative measurement.

1964 Helsinki declaration and its later amendments or comparable ethical standards. Informed consent was obtained from all individual participants included in the study.

Statistical analysis. Graphpad Software SPSS ${ }^{\circledR}$ (Statistical Package for Social Studies) version 22.0 (IBM Corporation, Chicago, IL, USA) was used for the statistical analysis. The one tail paired t test was used to compare the thickness and the stiffness measurements of the patients with ankylosing spondylitis with those of the controls. Significance was set at $\mathrm{p}<0.05$.

\section{Results}

The control group and the AS patients were well matched for age and clinical features. Five patients presented with calcaneal enthesophytes, and three patients with both enthesophytes and retrocalcaneal bursitis on the right Achilles tendon. In the control group, 10 participants had calcaneal enthesophytes in the right tendon, and one participant had a retrocalcaneal bursitis.

Regarding the left tendon, four patients presented with calcaneal enthesophytes; four patients presented with retrocalcaneal bursitis, and two presented with both retrocalcaneal bursitis and enthesophytes. In the controls, there were 8 patients with enthesophytes.

Power Doppler and SMI were negative in all patients and controls, for both the right and the left tendons.

At B mode ultrasound, the Achilles tendons of AS patients were significantly thicker than those of the control group only when the measurement was performed at the middle third of the tendon (Table II).

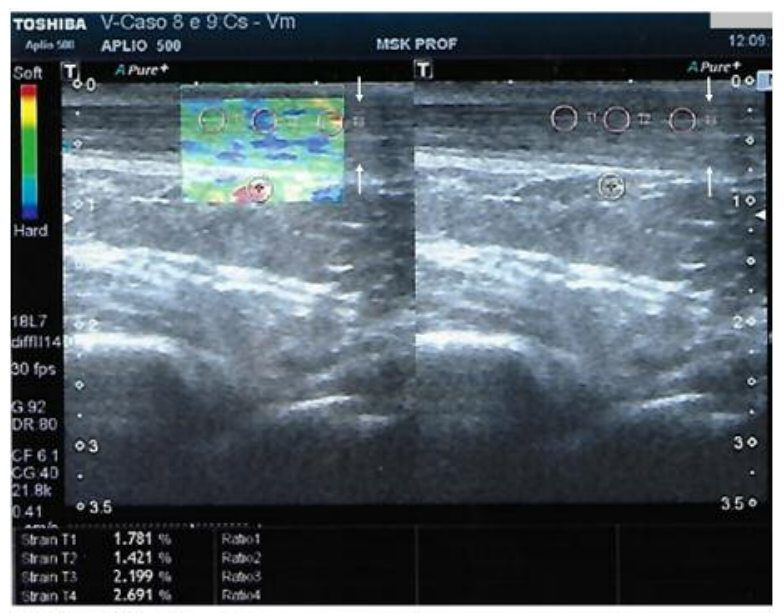

Figure 2. Longitudinal strain ultrasound elastography image of Achilles tendon of another AS patient. The superficial and deep surfaces of the Achilles tendon are identified with white arrows. The stiffness of Achilles tendon is measured in three points ( $Q$-Boxes), and compared with another point (Q-Box) in the deep tissue.

No significant differences were found between the tendon stiffness of the patients and the controls (Table II).

\section{Discussion}

Ultrasound is highly sensitive in detecting inflammatory lesions, signs of acute and chronic inflammation, neovascularization and enthesitis, thus facilitating appropriate diagnosis and management $(3,4,6,8,23,24)$. However, ultrasound cannot reveal early changes in the mechanical properties of tendon.

Ultrasound elastography has gained interest because it can provide qualitative and quantitative measurements of stiffness that reveal early modifications in the mechanical properties of tissues $(14,17,18)$. Interestingly, the use of ultrasound elastography in a rabbit experimental model of Achilles tendon transection was useful in quantifying mechanical and histological properties of the healing tendon (25). There are conflicting results regarding the repeatability of the use of shear-wave elastography to estimate the stiffness of the Achilles tendon, probably due to the underlying fiber architecture of this tendon (26). However, quantitative strain elastography has provided reproducible results when used to measure the elasticity of the Achilles tendon (27). Taking into consideration the poor information on the Achilles tendon stiffness in AS patients after treatment, elasticity of tendon measurements were performed in AS patients two years after the start of treatment with TNF- $\alpha$ antagonists, and compared with the results obtained from controls. Strain ultrasound elastography may distinguish healthy tendons from injured ones, and it also has higher sensitivity, compared with the 
conventional ultrasound, to detect early tendinopathy (28). Furthermore, strain elastography has higher accuracy in detecting Achilles tendinopathy in comparison to conventional B mode and color Doppler ultrasound (29).

The thickness of the Achilles tendon in AS patients and controls was not significantly different, except when measurements were made at the middle third of the tendon. At this site, there was a significant increase in thickness in the tendons of AS patients compared to the controls. However, power Doppler and SMI revealed that in all tendons of the patients and controls there was absence of vascularization, and the values of tendon stiffness of patients and controls overlapped. These results point towards a beneficial role of TNF- $\alpha$ antagonists for AS patients. Achilles tendinopathy and enthesitis are frequent in AS patients who have higher indices of disease activity and a decline in functional capacity and quality of life $(30,31)$. Sclerosing injections used in the management of patients with chronic overuse tendinopathy $(32,33)$, are not effective in patients with AS, for whom only TNF- $\alpha$ antagonist therapy showed some effects in reducing the severity of Achilles enthesitis and retrocalcaneal bursitis (34). In this study, we found that TNF- $\alpha$ antagonists may be associated with similar stiffness of the Achilles tendon in AS patients compared to controls.

Non-steroidal anti-inflammatory drugs are the first line of treatment (35). At Doppler ultrasound, evidence of a statistically significant positive association was found between entheseal inflammation of the Achilles tendon and activity indices of inflammation in AS patients, suggesting that Doppler ultrasound might be used to monitor the evolution of AS (36).

Power Doppler is very sensitive in the detection of inflammatory process in Achilles tendon including early stages (10); strain elastography might help to identify early modifications in mechanical properties of Achilles tendon, due to inflammatory injury in AS patients. Strain ultrasound elastography is a promising and valid tool that could be employed as a complementary instrument to power Doppler and SMI.

A possible bias of this preliminary study could be the relatively advanced age of the AS patients and controls. Indeed, Achilles tendon deforms with old age and may, therefore, become stiffer $(37,38)$ despite treatment. The fact that the Achilles tendon of our AS group was not harder than that of controls suggests that, in AS, changes in mechanical properties and tendon inflammation may be mitigated by $\mathrm{TNF} \alpha$ antagonists.

In the future, it would be interesting to perform longitudinal studies to investigate when the mechanical properties of the Achilles tendon start to change in AS patients. This could aid in determining whether more aggressive treatment must be implemented, thus preventing possible alterations in tendon structure.
A major limitation of this investigation is the low number of patients involved: obviously, these findings have to be regarded as preliminary, and need to be substantiated by larger studies. Long term longitudinal studies using strain ultrasound elastography might help clinicians to assess the risk of rupture of the Achilles tendon in AS patients.

We are aware that, as with all ultrasound techniques, strain elastography is operator dependent. It can be difficult to control the magnitude of the applied stress. Manual compression is operator dependent, although the amount and uniformity of the compression may be standardized via the observation of a pressure graph shown on the screen. Furthermore, other technical limitations such as shadowing, reverberation, clutter artifacts and strain concentration artifacts around specific structures, may reduce the reproducibility of ultrasound application.

\section{Conclusion}

In this descriptive report, it was observed that the tendon stiffness of AS patients treated with TNF $\alpha$ antagonists was not different from that of control patients. This result suggests a possible beneficial role of these drugs which will have to be confirmed in further studies.

\section{Conflicts of Interest}

The Authors declare that they have no conflicts of interest regarding this study.

\section{Author's Contributions}

EMZ carried out the ultrasound study, conceived and designed the study and drafted the manuscript. MEP participated in the design and conception of the study, performed the statistical analysis and drafted the manuscript. CG participated in the design and conception of the study, performed the statistical analysis and drafted the manuscript. AAF participated in the design and coordination of the study and drafted the manuscript. NMF participated in the conception and design of the study and drafted the manuscript, FF participated in the design, conception and coordination of the study and helped to draft the manuscript. All Authors read and approved the final manuscript and have agreed to be accountable for all aspects of the work if questions arise related to its accuracy or integrity.

\section{References}

1 Weber U, Jurik AG, Lambert RG and Maksymowych WP: Imaging in spondyloarthritis: Controversies in recognition of early disease. Curr Rheumatol Rep 18: 58, 2016. PMID: 27435070. DOI: $10.1007 / \mathrm{s} 11926-016-0607-7$

2 Balint PV, Kane D, Wilson H, McInnes IB and Sturrock RD: Ultrasonography of entheseal insertions in the lower limb in spondyloarthropathy. Ann Rheum Dis 61: 905-910, 2002. PMID: 12228161. DOI: 10.1136/ard.61.10.905 
3 Terslev L, Naredo E, Iagnocco A, Balint PV, Wakefield RJ, Aegerter P, Aydin SZ, Bachta A, Hammer HB, Bruyn GA, Filippucci E, Gandjbakhch F, Mandl P, Pineda C, Schmidt WA and D'Agostino MA: Outcome measures in rheumatology ultrasound task force. Defining enthesitis in spondyloarthritis by ultrasound: Results of a Delphi process and of a reliability reading exercise. Arthritis Care Res (Hoboken) 66: 741-748, 2014. PMID: 24151222. DOI: 10.1002/acr.22191

4 D'Agostino MA: Ultrasound imaging in spondyloarthropathies. Best Pract Res Clin Rheumatol 24: 693-700, 2010. PMID: 21025089. DOI: 10.1016/j.berh.2010.05.003.

5 Canoso JJ, Wohlgethan JR, Newberg AH and Goldsmith MR: Aspiration of the retrocalcaneal bursa. Ann Rheum Dis 43: 308312, 1984. PMID: 6712303.

6 D’Agostino MA, Aegerter P, Bechara K, Salliot C, Judet O, Chimenti MS, Monnet D, Le Parc JM, Landais P and Breban M: How to diagnose spondyloarthritis early? Accuracy of peripheral enthesitis detection by power Doppler ultrasonography. Ann Rheum Dis 70: 1433-1440, 2011. PMID: 21586438. DOI: 10.1136/ard.2010.138701

7 Balint PV, Mandl P and Kane D: All that glistens is not goldseparating artefacts from true Doppler signals in rheumatological ultrasound. Ann Rheum Dis 67: 141-142, 2008. PMID: 18192305. DOI: 10.1136/ard.2007.081554

8 McGonagle D, Benjamin M, Marzo-Ortega $\mathrm{H}$ and Emery P: Advances in understanding of entheseal inflammation. Current Rheumatol Rep 4: 500-506, 2002. PMID: 12427365.

9 Wang CH, Feng Y, Ren Z, Yang X, Jia JF, Rong MY, Li XY and Wu ZB. Performance of ultrasound to monitor Achilles enthesitis in patients with ankylosing spondylitis during TNF-a antagonist therapy. Clin Rheumatol 34: 1073-1078, 2015. PMID: 25896532. DOI: $10.1007 / \mathrm{s} 10067-015-2939-5$

10 Wink F, Bruyn GA, Maas F, Griep EN, van der Veer E, Bootsma $\mathrm{H}$, Brouwer E, Arends S and Spoorenberg A: Ultrasound evaluation of the entheses in daily clinical practice during tumor necrosis factor- $\alpha$ blocking therapy in patients with ankylosing spondylitis. J Rheumatol 44: 587-593, 2017. PMID: 28298566. DOI: $10.3899 /$ jrheum.160584

11 Gennisson JL, Deffieux T, Fink M and Tanter M: Ultrasound elastography: principles and techniques. Diagn Interv Imaging 94 : 487-495, 2013. PMID: 23619292. DOI: 10.1016/j.diii.2013. 01.022

12 Shiina T, Nightingale KR, Palmeri ML, Hall TJ, Bamber JC, Barr RG, Castera L, Choi BI, Chou YH, Cosgrove D, Dietrich CF, Ding H, Amy D, Farrokh A, Ferraioli G, Filice C, FriedrichRust M, Nakashima K, Schafer F, Sporea I, Suzuki S, Wilson S and Kudo M: WFUMB guidelines and recommendations for clinical use of ultrasound elastography: Part 1: basic principles and terminology. Ultrasound Med Biol 41: 1126-1147, 2015. PMID: 25805059. DOI: 10.1016/j.ultrasmedbio.2015.03.009

13 Sigrist RMS, Liau J, Kaffas AE, Chammas MC and Willmann JK: Ultrasound elastography: review of techniques and clinical applications. Theranostics 7: 1303-1329, 2017. PMID: 28435 467. DOI: 10.7150thno. 18650

14 Correas JM, Drakonakis E, Isidori AM, Hélénon O, Pozza C, Cantisani V, Di Leo N, Maghella F, Rubini A, Drudi FM and D'ambrosio F: Update on ultrasound elastography: Miscellanea, prostate, testicle, muscolo-skeletal. Eur J Radiol 82: 1904-1912, 2013. PMID: 23816164. DOI: 10.1016/j.ejrad.2013.05.031

15 Rist $\mathrm{H}$ and Mauch M: Quantified TDI elastography of the patellar tendon in athletes. Sportverletz Sportschaden 26: 27-32,
2012. PMID: 22422281. DOI: 10.1055/s-0031-1299109

16 Drakonaki EE, Allen GM and Wilson DJ: Real-time ultrasound elastography on the normal Achilles tendon: reproducibility and pattern description. Clin Radiol 64: 1196-1202, 2009. PMID: 19913130. DOI: $10.1016 /$ j.crad.2009.08.006

17 Klauser AS, Myamoto H, Tamegger M, Faschingbauer R, Moriggl B, Klima G, Feuchtner GM, Kastlunger M and Jaschke WR: Achilles tendon assessed with sonoelastography: histological agreement. Radiology 267: 837-842, 2013. PMID: 23449953. DOI: $10.1148 /$ radiol.13121936

18 Turan A, Tufan A, Mercan R, Teber MA, Tezcan ME, Bitik B, Goker B and Haznedaroğlu S: Real-time sonoelastography of Achilles tendon in patients with ankylosing spondylitis. Skeletal Radiol 42: 1113-1118, 2013. PMID: 23685710. DOI: 10.1007/ s00256-013-1637-0

19 Rudwaleit M, van der Heijde D, Landewe R, Listing J, Akkoc N, Brandt J, Braun J, Chou CT, Collantes-Estevez E, Dougados M, Huang F, Gu J, Khan MA, Kirazli Y, Maksymowych WP, Mielants H, Sørensen IJ, Ozgocmen S, Roussou E, Valle-Oñate R, Weber U, Wei J and Sieper J: The development of assessment of Spondyloarthritis international society classification criteria for axial spondyloarthritis (part II): Validation and final selection. Ann Rheum Dis 68: 777-783, 2009. PMID: 19297344. DOI: $10.1136 /$ ard.2009.108233

20 Braun J, Davis J, Dougados M, Sieper J, van der Linden S, van der Heijde D and ASAS Working Group: First update of the international ASAS consensus statement for the use of anti-TNF agents in patients with ankylosing spondylitis. Ann Rheum Dis 65: 316-320, 2006. PMID: 16096328. DOI: 10.1136/ard. 2005.040758

21 Wakefield RJ, Balint PV, Szkudlarek M, Filippucci E, Backhaus M, D’Agostino MA, Sanchez EN, Iagnocco A, Schmidt WA, Bruyn GA, Kane D, O'Connor PJ, Manger B, Joshua F, Koski J, Grassi W, Lassere MN, Swen N, Kainberger F, Klauser A, Ostergaard M, Brown AK, Machold KP and Conaghan PG: OMERACT 7 Special Interest Group: Musculoskeletal ultrasound including definitions for ultrasonographic pathology. J Rheumatol 32: 2485-2487, 2005. PMID: 16331793.

22 Herbert RD, Clarke J, Kwah LK, Diong J, Martin J, Clarke EC, Bilston LE and Gandevia SC: In vivo passive mechanical behaviour of muscle fascicles and tendons in human gastrocnemius muscle-tendon units. J Physiol 589(Pt21): 5257-5267, 2011. PMID: 21825027. DOI: 10.1113/physiol.2011. 212175

23 Delzell PB, Tritle BA, Bullen JA, Chiunda S and Forney MC: Clinical utility of high-frequency musculoskeletal ultrasonography in foot and ankle pathology: how ultrasound imaging influences diagnosis and management. J Foot Ankle Surg 56: 735-739, 2017. PMID: 28479161. DOI: 10.1053/i.fas.2017.01.052

24 Milutinovic S, Radunovic G, Veljkovic K, Zlatanovic M, Zlatkovic Svenda M, Perovic Radak M, Pavlov Dolijanovic S, Stojic B and Damjanov N: Development of ultrasound enthesitis score to identify patients with enthesitis having spondyloarthritis: prospective, double-blinded, controlled study. Clin Exp Rheumatol 33: 812-817, 2015. PMID: 26344397.

25 Yamamoto Y, Yamaguchi S, Sasho T, Fukawa T, Akatsu Y, Akagi R, Yamaguchi T, Takahashi K, Nagashima K and Takahashi K: Quantitative US elastography can be used to quantify mechanical and histologic tendon healing in a rabbit model of achilles tendon transection. Radiology 283: 408-417, 2017. PMID: 28145809. DOI: 10.1148/radiol.2016160695 
26 Peltz CD, Haladik JA, Divine G, Siegal D, van Holsbeeck M and Bey MJ: ShearWave elastography: repeatability for measurement of tendon stiffness. Skeletal Radiol 42: 1151-1156, 2013. PMID: 23640400. DOI: 10.1007/s00256-013-1629-0.

27 Yamamoto Y, Yamaguchi S, Sasho T, Fukawa T, Akatsu Y, Nagashima $\mathrm{K}$ and Takahashi K: Quantitative ultrasound elastography with an acoustic coupler for achilles tendon elasticity: measurement repeatability and normative values. J Ultrasound Med 35: 159-166, 2016. PMID: 26657752. DOI: 10.1007/s00776-015-0749-x

28 Ooi CC, Malliaras P, Schneider ME and Connell DA: Soft, hard, or just right? Applications and limitations of axial-strain sonoelastography and shear-wave elastography in the assessment of tendon injuries. Skeletal Radiol 43: 1-12 2014. PMID: 23925561. DOI: 10.1007/s00256-013-1695-3

29 Ooi CC, Schneider ME, Malliaras P, Chadwick M and Connell DA: Diagnostic performance of axial-strain sonoelastography in confirming clinically diagnosed Achilles tendinopathy: comparison with B-mode ultrasound and color Doppler imaging. Ultrasound Med Biol 41: 15-25, 2015. PMID: 25438847. DOI: 10.1016/j.ultrasmedbio.2014.08.019

30 Carneiro S, Bortoluzzo A, Gonçalves C, Gonçalves C, Silva JA, Ximenes AC, Bértolo M, Ribeiro SL, Keiserman M, Skare T, Menin R, Azevedo V, Vieira W, Albuquerque E, Bianchi W, Bonfiglioli R, Campanholo C, Carvalho HM, Costa Id, Duarte A, Kohem C, Leite N, Lima SA, Meirelles ES, Pereira IA, Pinheiro MM, Polito E, Resende GG, Rocha FA, Santiago MB, Sauma Mde F, Valim V and Sampaio-Barros PD: Effect of enthesitis on 1505 Brazilian patients with spondyloarthritis. J Rheumatol 40: 1719-1725, 2013. PMID: 23858049. DOI: 10.3899/jrheum. 121145

31 Laatiris A, Amine B, Ibn Yacoub Y and Hajjaj-Hassouni N: Enthesitis and its relationships with disease parameters in Moroccan patients with ankylosing spondylitis. Rheumatol Int 32: 723-727, 2012. PMID: 21161533. DOI: 10.1007/s00296$010-1658-0$

32 Willberg L, Sunding K, Ohberg L, Forssblad M, Fahlström M and Alfredson $\mathrm{H}$ : Sclerosing injections to treat midportion Achilles tendinosis: a randomised controlled study evaluating two different concentrations of Polidocanol. Knee Surg Sports Traumatol Arthrosc 16: 859-864, 2008. PMID: 18633599. DOI: 10.1007/s00167-008-0579-x
33 Ebbesen BH, Mølgaard CM, Olesen JL, Gregersen HE and Simonsen O: No beneficial effect of Polidocanol treatment in Achilles tendinopathy: a randomised controlled trial. Knee Surg Sports Traumatol Arthrosc 26: 2038-2044, 2018. PMID: 28856388. DOI: $10.1007 / \mathrm{s} 00167-017-4675-7$

34 Aydin SZ, Karadag O, Filippucci E, Atagunduz P, Akdogan A, Kalyoncu U, Grassi W and Direskeneli H: Monitoring Achilles enthesitis in ankylosing spondylitis during TNF-alpha antagonist therapy: an ultrasound study. Rheumatology (Oxford) 49: 578582, 2010. PMID: 20040527. DOI: 10.1093/rheumatology/ kep410

35 Khan Ma, Garcia-Kutzbach A and Espinoza LR: Treatment of ankylosing spondylitis: a critical appraisal of nonsteroidal antiinflammatory drugs and corticosteroids. Am J Med Sci 343: 350352, 2012. PMID: 22543535. DOI: 10.1097/MAJ.0b013e $31825140 \mathrm{a} 7$

36 Falcao S, Castillo-Gallego C, Peiteado D, Branco J, Martín Mola E and de Miguel E: Can we use enthesis ultrasound as an outcome measure of disease activity in spondyloarthritis? A study at the Achilles level. Rheumatology (Oxford) 54: 15571562, 2015. PMID: 25296747. DOI: 10.1093/rheumatology/ keu399

37 Turan A, Teber MA, Yakut ZI, Unlu HA and Hekimoglu B: Sonoelastographic assessment of the age-related changes of the Achilles tendon. Med Ultrason 17: 58-61, 2015. PMID: 25745659. DOI: 10.11152/mu.2013.2066.171.ayt

38 Slane LC, Martin J, DeWall R, Thelen D and Lee K: Quantitative ultrasound mapping of regional variations in shear wave speeds of the aging Achilles tendon. Eur Radiol 27: 474482, 2017. PMID: 27236815. DOI: 10.1007/s00330-016-4409-0

Received May 7, 2019

Revised June 11, 2019

Accepted June 12, 2019 